\title{
Acute Appendicits in Pregnancy: Evaluation of 129 Patients During 20 years
}

\author{
Akin Onder ${ }^{\mathrm{a}, \mathrm{c}}$, Murat Kapan ${ }^{\mathrm{a}}$, Zulfu Arikanoglu ${ }^{\mathrm{a}}$, Muhammet Erdal Sak ${ }^{\mathrm{b}}$, Metehan Gumus ${ }^{\mathrm{a}}$, \\ Fatih Taskesen ${ }^{\mathrm{a}}$, Ibrahim Aliosmanoglua ${ }^{\mathrm{a}}$ Bilsel Bac ${ }^{\mathrm{a}}$
}

\begin{abstract}
Background: Acute appendicitis is the most common non-obstetric emergency requiring surgery during pregnancy, and delayed diagnosis is associated with a greater risk of fetal or maternal morbidity and fetal loss. The aim of this study is to analyze the diagnosis of acute appendicitis during pregnancy, along with maternal and fetal complications.
\end{abstract}

Methods: Between January 1990 and December 2010, 129 pregnant women who were operated on due to acute appendicitis were evaluated retrospectively.

Results: The mean age of patients was $28.3 \pm 6.6$ years, and the time from presentation of symptoms to admission was $41.1 \pm 33.2$ hours. The most common complaints were lower right quadrant pain $(66.7 \%)$ and nausea-vomiting $(65.1 \%)$. The most common physical signs were abdominal tenderness and rebound. Gestational stage at diagnosis was second trimester in 74 patients, first trimester in 31 patients, and third trimester in 24 patients. The perforation rate among our cases was $28.7 \%$. The perforation-associated with delayed admission to the hospital $(\mathrm{P}=0.001)$ was the most common in the first trimester with a rate of $40.5 \%$. Morbidity occurred in 41 patients $(31.8 \%)$. Fetal mortality occurred in $1(1.1 \%)$ of non-

Manuscript accepted for publication January 19, 2012

aDepartment Of Surgery, Dicle University Faculty Of Medicine, Turkey

${ }^{b}$ Department Of Obstetrics And Gynecology, Dicle University Faculty Of Medicine, Turkey

${ }^{\mathrm{c} C}$ Corresponding author: Akın Onder, Department of Surgery, Dicle University Faculty of Medicine, 21280, Diyarbakır, Turkey.

Email: draonder@gmail.com

doi: $10.4021 / \mathrm{jcs} 17 \mathrm{w}$ perforated patients, and in 5 of the perforated patients (13.5\%). No maternal mortality occurred. Mean hospital stay was $2.8 \pm 0.9$ days in non-perforated patients, while $5.3 \pm 2.2$ days in perforated patients $(\mathrm{P}=0.001)$.

Conclusions: Because of the nonspecific and pregnancy-attributed symptoms, acute appendicitis during pregnancy may result in an increased risk of fetomaternal morbidity and fetal mortality.

Keywords: Acute appendicitis; Pregnancy; Morbidity; Mortality

\section{Introduction}

Acute appendicitis is the most common non-obstetric emergency requiring surgery during pregnancy [1]. The incidences of acute appendicitis are similar in the pregnant and non-pregnant women, ranging from 1:1250 to $1: 1500[2,3]$. Acute appendicitis is diagnosed through anamnesis, physical examination, imaging tecniques, and laboratory parameters. However, the risk of delay in diagnosis, resulting from the absence of specific signs in physical examination and from anatomic and physiological changes, is associated with a greater risk of fetal or maternal morbidity and fetal loss $[4,5]$. The incidence rate of perforated appendicitis due to delayed diagnosis in preoperative period is greater in pregnant women $[6,7]$. The aim of the present study is to discuss acute appendicitis in pregnancy, along with maternal and fetal complications, in an attempt to present ideal medical approaches to be employed in patient management.

\section{Materials and Methods}

The retrospective study involved 129 pregnant women who received an operation following diagnosis of acute appendicitis in General Surgery Department from January 1990 to December 2010. All the patients received gynecological and obstetrical follow-up both pre- and post-operatively. Following a detailed anamnesis, abdominal and gynecological examinations were performed. Preoperatively, they 
Table 1. Demographic and Clinical Parameters of the Pregnant Women With Appendicitis

\begin{tabular}{lll}
\hline Parameters & Mean \pm SD & Minimum - Maximum \\
\hline Age (years) & $28.3 \pm 6.6$ & $16-45$ \\
Gravidity & $2.92 \pm 1.69$ & $1-8$ \\
Time I (h) & $41.1 \pm 33.2$ & $6-168$ \\
Time II (h) & $8.2 \pm 7.0$ & $1-36$ \\
\hline
\end{tabular}

Time I: Time from onset of symptoms to admission (h); Time II: Time from admission to operation (h); SD: Standard deviation.

underwent complete blood count (CBC), biochemical analyses, urinalysis, and abdominal ultrasonography (USG). Age, gestational age, gestational history, symptoms and signs, durations of symptoms, laboratory parameters, USG findings, time between admission through operation, surgical findings, histopathologic diagnosis, and morbidity-mortality rates were analyzed. Fetal heartbeat and well-being was followed by USG, both pre- and post-operatively. Plain X-ray and computed tomography were avoided due to their teratogenic effect on the fetus [7]. Patients were operated under spinal or general anesthesia, in such a way that their fetuses were exposed to the least amount of anesthetic drugs. All of them underwent appendectomy either through McBurney's or paramedian incision. The patients receive tocolytic medication after regular uterine contractions that commenced between 1990 and 2005, and as prophylactic in the third trimester between 2006 and 2010. In order to eliminate the risk of traumas for uterus, surgical operations were kept as short as possible. For complicated appendicitis cases, perapendicular regions were drained after surgery. All the cases received preoperative prophylactic 2 nd generation cephalosporin, while the complicated ones pursued their treatment till the fifth day with addition of metronidazole [7]. Patients were then discharged, and followed gynecologically and obstetrically.

\section{Statistical method}

Statistical analysis of data was performed by SPSS (SPSS for Windows 13.0, Chicago, IL, USA) software. The normality of distributions was evaluated with the KolmogorovSmirnov test. Student-t test was performed for parametric groups, while Mann-Whitney U-test for comparison of nonparametric and independent groups. Differences in categorical variables were assessed with Chi-square test or Fisher's exact test. Perforation-related risk factors were evaluated with logistic regression test. $\mathrm{P}<0.05$ was considered statistically significant, and odds-ratio (OR) was calculated for each variant.

\section{Results}

The mean age was $28.3 \pm 6.6(16-45)$ years. Time from onset of the symptoms to admission was $41.1 \pm 33.2$ (6 168) hours. Demographic and clinic data about patients are shown in Table 1. Abdominal pain (66.7\%) and nauseavomiting $(65.1 \%)$ were the most common complaints. Abdominal tenderness (100\%) and rebound (65.9\%) were the most common physical signs during physical examination. Mean white blood cell count (WBC) was $13978 \pm 3245$ $\mathrm{mm}^{3}$ (6000 - 25300). In USG results, 74 patients $(57.4 \%)$ had acute appendicitis, $21(16.3 \%)$ had appendicitis perforation, and $34(26.4 \%)$ proved non-diagnostic. The sensitivity and specificity of USG were found as $70.2 \%$ and $53.3 \%$, respectively. Positive and negative predictive values were found as $91.9 \%$ and $19 \%$, respectively. Symptoms, physical examination and laboratory parameters, and USG results are displayed in Table 2. Gestational stage at diagnosis was second trimester in 74 patients $(57.4 \%)$, first trimester in 31 patients $(24 \%)$, and third trimester in 24 patients $(18.6 \%)$. Time from presentation symptoms to admission was 81.03 \pm 32.50 hours for the perforated, while it was $25.05 \pm 15.09$ hours for the non-perforated. Statistical difference in perforation rate was considered significant $(\mathrm{P}=0.001)$. Demographic and clinic parameters compared to perforation are shown in Table 3. Operations confirmed acute appendicitis in $77(59.7 \%)$, and perforation in $37(28.7 \%)$, while the remaining $15(11.6 \%)$ had normal appendix. Among the ones with normal appendix, there were various etiologies including urinary tract infection (3), lymphadenitis (3), overian cyst rupture (2), tuba-ovarian abscess (2), and gastroenteritis (1) while 4 of them proved no etiology. For appendectomy, McBurney's incision was performed for 114 (88.6\%), while $15(11.6 \%)$ underwent paramedian incision. Histopathologic analyses confirmed acute appendicitis in 96\%. Perforation occurred in 37 patients (28.7\%). Among the patients, $40.5 \%$ were in first trimester, $28.6 \%$ in second trimester, and $10.8 \%$ in third trimester. In terms of perforation rate, the first trimester was found statistically associated with other trimes- 
Table 2. Symptoms and Findings of Physical, Laboratory and Ultrasonographic Examinations

\begin{tabular}{|c|c|c|}
\hline & $\mathbf{N}$ & $\%$ \\
\hline \multicolumn{3}{|l|}{ Symptoms } \\
\hline Right lower quadrant pain & 86 & 66.7 \\
\hline Right upper quadrant pain & 16 & 12.4 \\
\hline Right and left lower quadrant pain & 16 & 12.4 \\
\hline Diffuse abdominal pain & 26 & 20.2 \\
\hline Nausea and vomiting & 84 & 65.1 \\
\hline Dysuria & 26 & 20.2 \\
\hline Back pain & 2 & 1.6 \\
\hline Vaginal hemorrhage & 2 & 1.6 \\
\hline \multicolumn{3}{|l|}{ Physical Findings } \\
\hline Tenderness & 129 & 100 \\
\hline Rebound & 85 & 65.9 \\
\hline Tenderness and guarding & 85 & 65.9 \\
\hline \multicolumn{3}{|l|}{ White Blood Count } \\
\hline$<10,000 \mathrm{~mm}^{3}$ & 14 & 10.9 \\
\hline $10,000-15,000 \mathrm{~mm}^{3}$ & 65 & 50.4 \\
\hline$>15,000 \mathrm{~mm}^{3}$ & 50 & 38.7 \\
\hline \multicolumn{3}{|l|}{ Urinalysis } \\
\hline Leukocyturia & 74 & 57.4 \\
\hline Bacteriuria & 53 & 41.1 \\
\hline \multicolumn{3}{|l|}{ Ultrasound examination } \\
\hline Non-diagnostic & 34 & 26.3 \\
\hline Acute appendicitis & 74 & 57.4 \\
\hline Intra-abdominal fluid & 21 & 16.3 \\
\hline
\end{tabular}

ters $(\mathrm{P}=0.016)$. Postoperative morbidity occurred in 41 patients $(31.8 \%)$. These included $26.1 \%$ of 92 non-perforated patients and $48.6 \%$ of 37 perforated patients. Comparison between two groups was considered significant $(\mathrm{P}=0.013)$. Major complications were uterine contraction $(10.8 \%)$ and wound infection $(7.8 \%)$. Complications both for the perforated and the non-perforated are shown in Table 4. Of 14 patients with uterine contraction, 11 were in third trimester. Of 10 patients with risk of preterm labor, 8 were provided tocolytic drugs. Fetal mortality occurred in only $1(1.1 \%)$ patient in the non-perforated group, and in $5(13.5 \%)$ in the perforated. Of the losses in the perforated group, 1 was in the first (miscarriage), 3 in the second (miscarriage $(n=2)$ and still birth $(\mathrm{n}=1)$ ), and 1 in the third trimester (preterm delivery (who died shortly after the birth)). The patient in the non-perforated group, who was in first trimester, received medical abortion upon parental request. No postoperative maternal loss occurred in either group. Mean hospital stay in postoperative period was 3.4 days $(2-14)$. It was $2.8 \pm 0.9$ days ( 2 - 5) for the non-perforated, while $5.3 \pm 2.2$ days (3 $14)$ for the perforated. The difference between hospital stays was considered significant $(\mathrm{P}=0.001)$.

In univariate analyses, mean gestational age was 19.29 \pm 7.89 weeks for the non-perforated, and $15.14 \pm 8.33$ weeks for the perforated $(\mathrm{P}=0.009)$. Mean $\mathrm{WBC}$ was $13442 \pm$ $3262 / \mathrm{mm}^{3}$ in the non-perforated, and $15310 \pm 2823 \mathrm{~mm}^{3}$ in 
Table 3. Classification of Demographic and Clinical Parameters of the Patients in Terms of Perforation

\begin{tabular}{|c|c|c|c|}
\hline & Non-perforated (92) & Perforated (37) & $\mathbf{P}$ \\
\hline Age (years) & $28.39 \pm 6.60$ & $28.19 \pm 6.55$ & NS \\
\hline Gravidity & $2.83 \pm 1.62$ & $3.16 \pm 1.85$ & NS \\
\hline Gestational age (week) & $19.29 \pm 7.89$ & $15.14 \pm 8.33$ & 0.009 \\
\hline Time I (h) & $25.05 \pm 15.09$ & $81.03 \pm 32.50$ & 0.001 \\
\hline Time II (h) & $10.57 \pm 6.89$ & $2.32 \pm 1.45$ & 0.001 \\
\hline
\end{tabular}

Time I: Time from onset of symptoms to admission (h); Time II: Time from admission to operation (h); NS: Not Significant.

the perforated. $\mathrm{P}=0.003$ was considered statistically significant. In binary logistic regression analysis, time from onset of the symptoms to admission for both groups was $(\mathrm{P}=$ $0.001, \mathrm{OR}=1.13,95 \% \mathrm{Cl}=1.07$ - 1.19.) Gestational weeks were $(\mathrm{P}=0.595, \mathrm{OR}=1.03,95 \% \mathrm{Cl}=0.93$ - 1.159.) Other variants are shown in Table 5.

\section{Discussion}

Acute appendicitis is the most common non-obstetric emergency requiring surgery during pregnancy, with an incidence rate of $25 \%[5,8]$. Common symptoms are similar to the ones with pregnancy, which complicate the diagnosis of pregnant patients $[1,9,10]$. The first and early second trimesters are much like to the non-pregnant period in terms of appendicial symptoms and signs [11]. Also, physical examinations during pregnancy may produce different results due to anatomic displacement of appendix [12-14]. In accordance with the growing uterus in later weeks of pregnancy, appendix moves up towards the lateral, causing a tension in the anterior abdominal wall. Thus, it becomes difficult to achieve a clear assessment of defense and rigidity during physical examination [15]. Hodjati et al. [16] and Terzi et al. [17] have reported that the pain in the lower right quadrant occurs more frequently in third trimester. In the present study, the pain in the lower quadrant was $66.7 \%$. In our patients, tenderness was observed in all, while rebound in $65.9 \%$. According to Popkin et al. [7], McBurney's incision provides an easy access to appendicitis in $94 \%$ of patients. In $88.4 \%$ of our patients, McBurney's incision confirmed normal appendix localization. Accordingly, we considered that the physical signs and symptoms did not change even in the third trimester and that the appendix is easily accessible via McBurney's incision. It has been reported that, acute appendicitis is most common in the second and third trimesters $[5,18]$. That $57.4 \%$ of

Table 4. Postoperative Complications for Both Groups

\begin{tabular}{lcc}
\hline & $\begin{array}{c}\text { Perforated } \\
\text { (n) }\end{array}$ & $\begin{array}{c}\text { Non-perforated } \\
\text { (n) }\end{array}$ \\
\hline Uterine contraction & 2 & 12 \\
Wound infection & 8 & 2 \\
Preterm labor & 1 & 9 \\
Paralytic ileus & 4 & - \\
Evisceration & 1 & - \\
Acute Respiratory Distress Syndrome & - & - \\
Sepsis & 1 & 1 \\
\hline
\end{tabular}




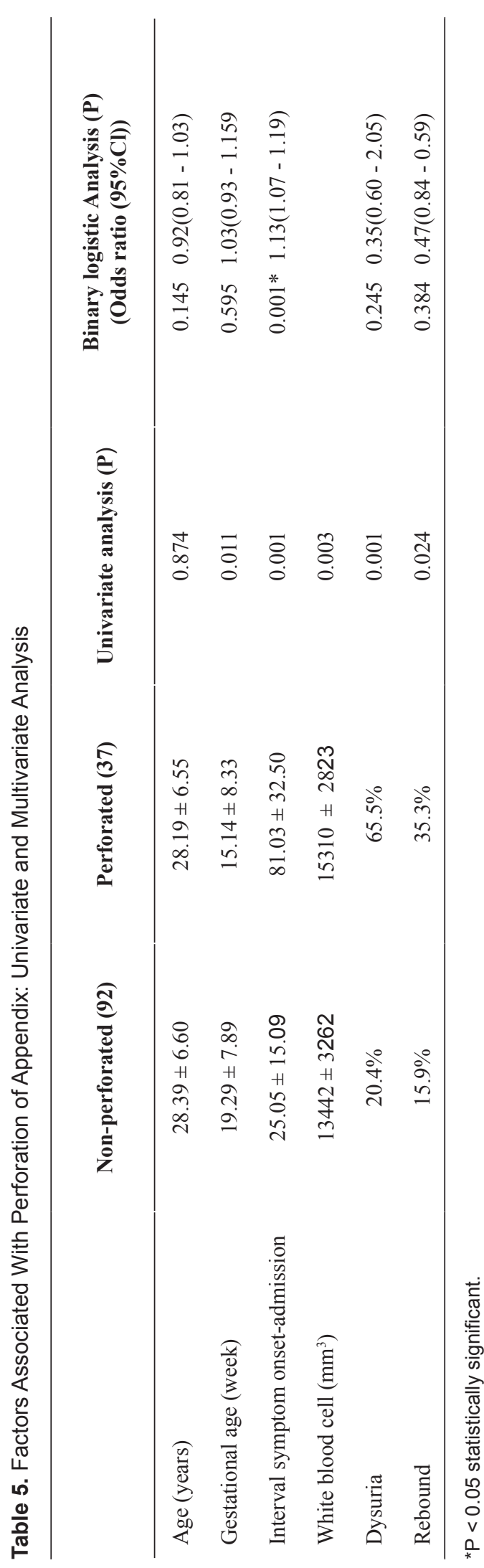

our patients were in second trimester was consistent with the literature. The case of acute appendicitis during pregnancy is primarily attributed to pregnancy, which causes a delay in diagnosis $[1,10]$. It is though to be that the abdominal tension caused by uterus growth in the third trimester obscures the physical examination signs, which causes higher perforation rates as a result of delay in diagnosis [12-15]. Adversely, we found a higher perforation rate for the first weeks of pregnancy. In the perforated group, 15 (40.5\%) were in the first trimester. Of these, $40 \%$ of them were experiencing their first pregnancy. Perforation is observed more frequently in the first trimester and mostly during the first experience of pregnancy, which implies that the complaints are mistakenly regarded as pregnancy-related symptoms and thus the patients receive their initial intervention in gynecology department. As for the frequent perforation in pregnancy, it could be attributed to the fact that patients refrain from surgical interventions while insisting on medication instead, and that doctors assume a more conservative attitude towards them. Laboratory studies play a limited role in sensitivity and specificity of diagnosis. Leukocytosis is difficult to interpret because of the physiological leukocytosis during pregnancy [13, 19]. Anderson et al. [20] reported the normal level of leukocytosis as up to $16.000 / \mathrm{mm}^{3}$. In addition, hematuria or bacteriuria could be detected in urine, which is a complicating issue for such patient groups. Leukocytosis was confirmed over $15.000 / \mathrm{mm}^{3}$ in $38.7 \%$ of our series, and, as consistent with in the literature, leukocyturia and bacteriuria were observed in $57.4 \%$ and $41.1 \%$ of our patients, respectively.

USG is the most common imaging test used in diagnosis of acute appendicitis in pregnant patients in that it can often visualize an inflamed appendix without any risk to the fetus [21]. USG presents great sensitivity and specificity particularly in early periods of pregnancy [22]. Lim et al. [23] reported the sensitivity, specificity, and accuracy of ultrasonography to be $100 \%, 96 \%$, and $98 \%$, respectively. However, appendix displacement, obesity, and technical challenges depending on the overgrowth of uterus and intervening intestinal gas for USG decrease the diagnostic value of USG in the third trimester [5]. Mazze et al. [2] found ultrasonography to be nondiagnostic in $70 \%$ of patients during pregnancy. USG verified the sensitivity, specificity and accuracy rate of the diagnosis of our patients as $70.2 \%, 53.3 \%$, and $73.7 \%$, respectively. Nonetheless, USG is reported not to be the gold standard and cannot rule out if the appendix is negative.

CT is more useful than the USG in the diagnosis of appendicitis in pregnancy. However, the radiation exposure during a CT scan may lead to a slight increase in the risks of fetal malformation and leukemia in the childhood period [24]. Therefore, CT scans were avoided in our series.

Differential diagnosis of acute appendicitis may provide various conditions: (I) medical emergencies (porphyria, dia- 
betic ketoacidosis, glomerulonephritis, pyelonephritis); (II) gynecological emergencies (overian cyst rupture, tubaovarian abscess, fallopian tube torsion); (III) non-gynecological emergencies (mesenteric lymphadenitis, acute cholecystitis, acute pancreatitis, peptic ulcus perforation, intestinal obstruction); and (IV) obstetrical emergencies (preterm labor, ectopic pregnancy, preeclampsia) $[3,25]$. In our study, urological, gynecological, and intestinal conditions were investigated in the differential diagnosis, and appropriate treatments were performed accordingly. Yet, no etiology was found in four cases although they were analyzed for familial mediterranean fever.

Acute patients should be promptly evaluated and diagnosed so as to prevent perforation and negative laparotomies $[6,14,15]$. Prompt intervention to be performed within 24 hours after the onset of symptoms will reduce the risk of fetomaternal morbidity and fetal mortality. A post-24-hours delay increases the risks of perforation, fetal loss, and maternal morbidity $[1,3]$. High rates of perforation were confirmed in our delayed patients. Perforation rate and negative laparotomy rate during pregnancy are reported to be $12-55 \%$ $[6,14,15]$ and $13-50 \%[17,19]$, respectively. We found the perforation rate as $28.7 \%$ and negative laparotomy as $11.6 \%$ between 2005 - 2010 in our department. In the same department, Yilmaz et al. [26] assessed perforation as $40 \%$ and negative laparotomy as 4\% between 1990 - 2005. Technical advances, expanding opportunities in accessing healthcare services and educational improvements have decreased the perforation risk while increasing negative laparotomies on the other hand. Frequent postoperative complications are uterine contraction, preterm labor and wound infection, while preterm delivery is rare $[5,10,13]$. Morbidity rate with the non-perforated and the perforated groups are $10 \%$ and $35-40 \%$, respectively $[27,28]$. We found them as $26.1 \%$ and $48.6 \%$. Both pre- and postoperatively, tocolytic medication is reported to prevent post-appendectomy preterm labor [2, 20]. Adversely, Hee et al. [29] reported the tocolytic medication as useless. However, we found the preventive rate of tocolytic medication as $46 \%$ till 2005 , which later climbed up to $70 \%$ between 2005 - 2010 with the aid of prophylactic usage. Wound infections recovered with wound care and antibiotics. In these patients, there was no gestational problem detected via fetal ultrasonography. Postoperative incidences of paralytic ileus were treated conservatively. Only one patient had the incidence of evisceration, whose skin was covered only and which later underwent repair in incisional hernia in suitable conditions. The cases of acute respiratory distress syndrome and sepsis were healed through medical treatment and respiratory exercises.

Fetal mortality rate is reported to be $3-5 \%$ in non-perforated groups, and $20-35 \%$ in perforated groups [30, 31]. The rate in our study was found as $13.5 \%$ in the perforated, while the non-perforated group consisted of one patient who received medical abortus upon parental request. Fetal loss may result from increased movements of uterus or it may arise because the omentum cannot isolate the peritonitis, which is in turn caused by the perforation resulting from delayed diagnosis and intervention [10, 32]. In spite of fetal losses and morbidity, there was no maternal loss in our study, likely because of antibiotics usage, advances in anesthesia, and improvements in pre- and post-operative healthcare services.

\section{Conclusion}

Nonspecific symptoms or signs, along with the complaints that are attributed to pregnancy, may result in delay in diagnosis, causing more frequent perforations. Physical examination remains useful in the diagnosis of classical acute appendicitis in that it reveals the lower quadrant pain and rebound positive during pregnancy. Regardless of anatomic changes, McBurney's incision enables easy access to appendicitis. The third trimester group could be provided with tocolytic medication so as to prevent uterine contractions and preterm labor. Perforation is likely to occur more frequently in early periods of pregnancy. Perforation increases the risk of fetomaternal morbidity and fetal mortality. Thus, cases with a suspicion of acute appendicitis should be wellmonitored and followed, and if needed, should be promptly operated with a multidisciplinary surgical approach.

\section{Conflict of Interest}

All authors declare that there is no conflict of interest.

\section{References}

1. Zhang Y, Zhao YY, Qiao J, Ye RH. Diagnosis of appendicitis during pregnancy and perinatal outcome in the late pregnancy. Chin Med J (Engl). 2009;122(5):521-524.

2. Mazze RI, Kallen B. Appendectomy during pregnancy: a Swedish registry study of 778 cases. Obstet Gynecol. 1991;77(6):835-840.

3. Tamir IL, Bongard FS, Klein SR. Acute appendicitis in the pregnant patient. Am J Surg. 1990;160(6):571-575; discussion 575-576.

4. Basaran A, Basaran M. Diagnosis of acute appendicitis during pregnancy: a systematic review. Obstet Gynecol Surv. 2009;64(7):481-488; quiz 499.

5. Mourad J, Elliott JP, Erickson L, Lisboa L. Appendicitis in pregnancy: new information that contradicts long-held clinical beliefs. Am J Obstet Gynecol. 2000;182(5):1027-1029.

6. Ueberrueck T, Koch A, Meyer L, Hinkel M, Gastinger I. Ninety-four appendectomies for suspected acute appendicitis during pregnancy. World J Surg. 2004;28(5):508- 
511.

7. Pastore PA, Loomis DM, Sauret J. Appendicitis in pregnancy. J Am Board Fam Med. 2006;19(6):621-626.

8. Dietrich CS, 3rd, Hill CC, Hueman M. Surgical diseases presenting in pregnancy. Surg Clin North Am. 2008;88(2):403-419, vii-viii.

9. Al-Mulhim AA. Acute appendicitis in pregnancy. A review of 52 cases. Int Surg. 1996;81(3):295-297.

10. Atila K, Ucar AD, Unek T, Sevinc A, Cevik AA, Sokmen S. [Acute appendicitis in pregnancy]. Ulus Travma Derg. 2002;8(2):98-101.

11. Coleman MT, Trianfo VA, Rund DA. Nonobstetric emergencies in pregnancy: trauma and surgical conditions. Am J Obstet Gynecol. 1997;177(3):497-502.

12. Tracey M, Fletcher HS. Appendicitis in pregnancy. Am Surg. 2000;66(6):555-559; discussion 559-560.

13. Somani RA, Kaban G, Cuddington G, McArthur R. Appendicitis in pregnancy: a rare presentation. CMAJ. 2003;168(8):1020.

14. Popkin CA, Lopez PP, Cohn SM, Brown M, Lynn M. The incision of choice for pregnant women with appendicitis is through McBurney's point. Am J Surg. 2002;183(1):20-22.

15. Eryilmaz R, Sahin M, Bas G, Alimoglu O, Kaya B. Acute appendicitis during pregnancy. Dig Surg. 2002;19(1):4044.

16. Hodjati H, Kazerooni T. Location of the appendix in the gravid patient: a re-evaluation of the established concept. Int J Gynaecol Obstet. 2003;81(3):245-247.

17. Terzi A, Yildiz F, Vural M, Coban S, Cece H, Kaya M. A case series of 46 appendectomies during pregnancy. Wien Klin Wochenschr. 2010;122(23-24):686-690.

18. Andersson RE, Lambe M. Incidence of appendicitis during pregnancy. Int J Epidemiol. 2001;30(6):1281-1285.

19. Melnick DM, Wahl WL, Dalton VK. Management of general surgical problems in the pregnant patient. Am J Surg. 2004;187(2):170-180.

20. Andersen B, Nielsen TF. Appendicitis in pregnancy: diagnosis, management and complications. Acta Obstet
Gynecol Scand. 1999;78(9):758-762.

21. Williams R, Shaw J. Ultrasound scanning in the diagnosis of acute appendicitis in pregnancy. Emerg Med J. 2007;24(5):359-360.

22. Kaakaji Y, Nghiem HV, Nodell C, Winter TC. Sonography of obstetric and gynecologic emergencies: Part II, Gynecologic emergencies. AJR Am J Roentgenol. 2000;174(3):651-656.

23. Lim HK, Bae SH, Seo GS. Diagnosis of acute appendicitis in pregnant women: value of sonography. AJR Am J Roentgenol. 1992;159(3):539-542.

24. Miller JC. Risks from ionizing radiation in pregnancy. Radiology Rounds 2004;2:1-3.

25. Hauptmann J, Mechtersheimer G, Blaker H, Schaupp W, Otto HF. [Deciduosis of the appendix. Differential diagnosis of acute appendicitis]. Chirurg. 2000;71(1):89-92.

26. Yilmaz HG, Akgun Y, Bac B, Celik Y. Acute appendicitis in pregnancy--risk factors associated with principal outcomes: a case control study. Int J Surg. 2007;5(3):192197.

27. McGory ML, Zingmond DS, Tillou A, Hiatt JR, Ko CY, Cryer HM. Negative appendectomy in pregnant women is associated with a substantial risk of fetal loss. J Am Coll Surg. 2007;205(4):534-540.

28. Wittich AC, DeSantis RA, Lockrow EG. Appendectomy during pregnancy: a survey of two army medical activities. Mil Med. 1999;164(10):671-674.

29. Hee P, Viktrup L. The diagnosis of appendicitis during pregnancy and maternal and fetal outcome after appendectomy. Int J Gynaecol Obstet. 1999;65(2):129-135.

30. Firstenberg MS, Malangoni MA. Gastrointestinal surgery during pregnancy. Gastroenterol Clin North Am. 1998;27(1):73-88.

31. Visser BC, Glasgow RE, Mulvihill KK, Mulvihill SJ. Safety and timing of nonobstetric abdominal surgery in pregnancy. Dig Surg. 2001;18(5):409-417.

32. Tarraza HM, Moore RD. Gynecologic causes of the acute abdomen and the acute abdomen in pregnancy. Surg Clin North Am. 1997;77(6):1371-1394. 